\title{
Correction to: Molecular basis for efficacy of Guduchi and Madhuyashti feeding on different environmental stressors in Drosophila
}

\section{Surabhi Singh ${ }^{1} \cdot$ Madhu G. Tapadia $^{1}$}

Published online: 25 November 2019

(C) Cell Stress Society International 2019

\section{Correction to: Cell Stress and Chaperones (2019) 24:549-565}

https://doi.org/10.1007/s12192-019-00986-0

It has come to authors' attention that an inadvertent mistake was made in the construction of Figure 4 and Figure 6 of the original publication. The corrected figures are shown here and should be used in place of the previously published figure.

The online version of the original article can be found at https://doi.org/ 10.1007/s12192-019-00986-0

Madhu G. Tapadia

madhu@bhu.ac.in

Surabhi Singh

surabhisingh55555@gmail.com; surabhi.singh3@bhu.ac.in

1 Cytogenetics Laboratory, Department of Zoology, Banaras Hindu

University, Varanasi, Uttar Pradesh, India 


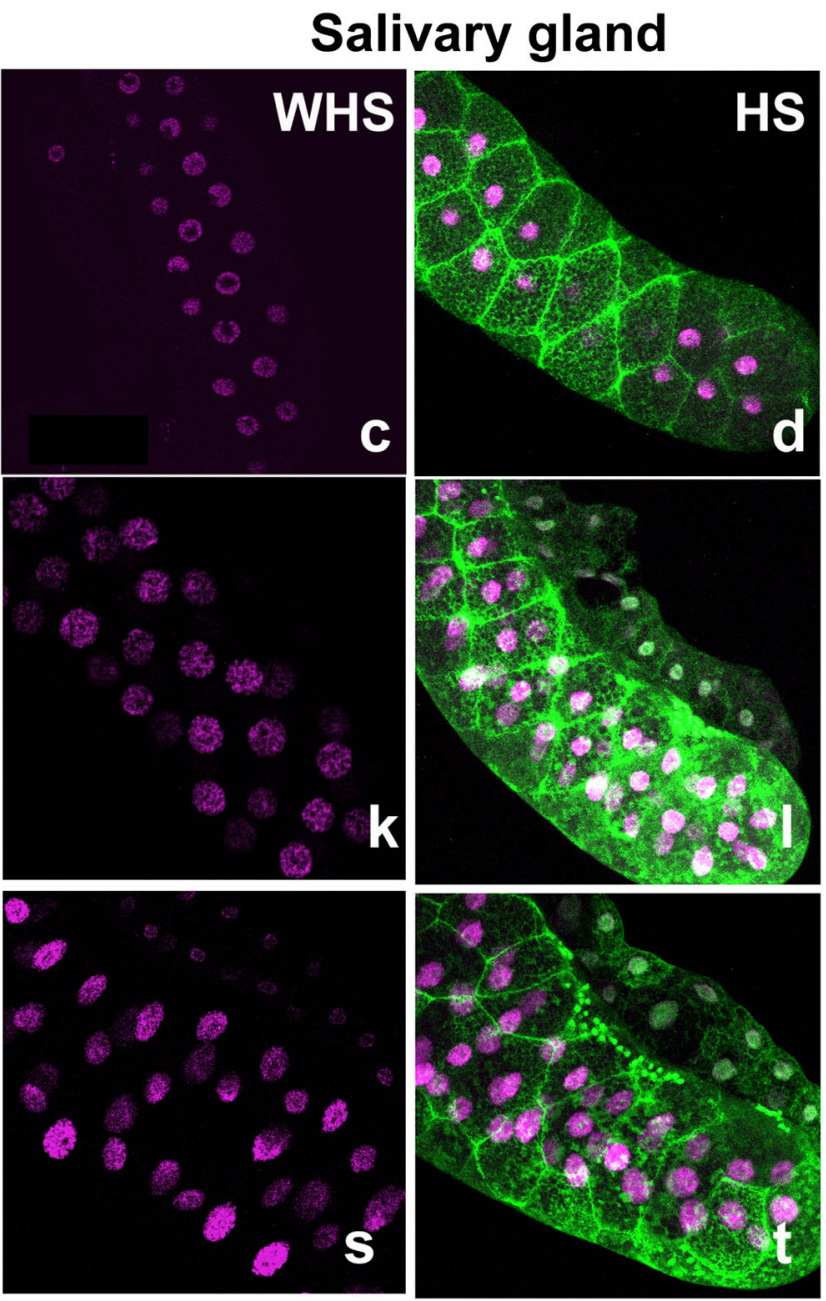

Fig. 4a In the panel of Salivary glands, panels $\mathbf{k}$ and $\mathbf{s}$ have been replaced

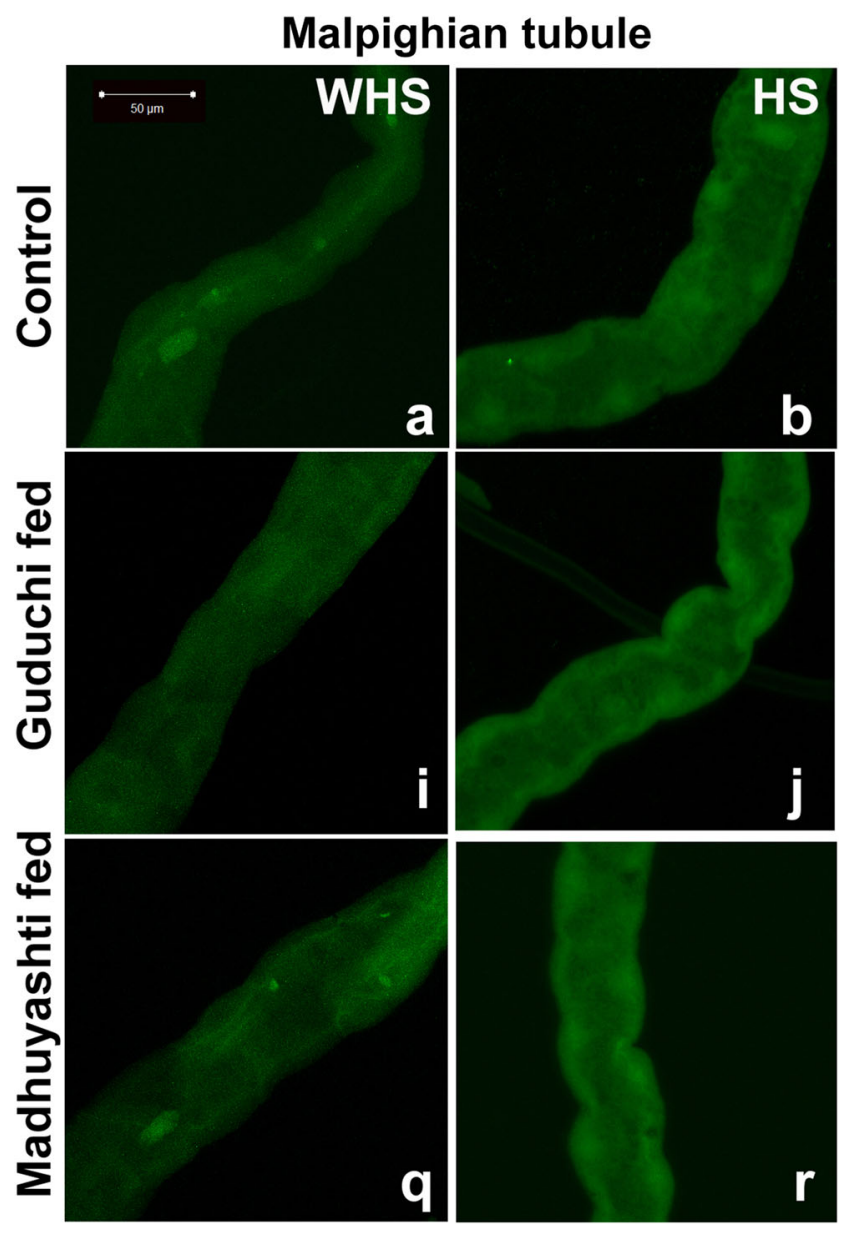

Fig. 6a In the panel of Malpighian tubule panels $\mathbf{b}$, $\mathbf{j}$ and $\mathbf{r}$ (HS) have been replaced 